\title{
Sampling variability of percutaneous liver biopsy in primary sclerosing cholangitis
}

\author{
R Olsson, I Hägerstrand, U Broomé, Å Danielsson, G Järnerot, L Lööf, H Prytz, \\ B-O Rydén, $S$ Wallerstedt
}

\begin{abstract}
Aims-To study sampling variability of percutaneous liver biopsy in primary sclerosing cholangitis (PSC).

Methods-One hundred and twelve biopsy specimens (that is, 56 pairs) from 44 patients with PSC, confirmed by cholangiography, were evaluated blindly. Six different features, qualitative grading of four other features and staging according to Ludwig were assessed.

Results-Quantitative sampling variability was confined mainly to just one grade or stage, although $11 \%$ (six of 56 ) of the biopsy specimen pairs differed by more than one stage (7\% (one of 15$)$ in pairs $>2 \mathrm{~cm}$ in length). Qualitative sampling variabilities were between 18 and $71 \%$. Advanced disease (stages 3 or 4 ) was missed in $40 \%$ (two of five) of the biopsy specimens while cirrhosis was missed in $37 \%$.

Conclusion-Paired liver biopsy specimens should be taken in clinical studies of PSC using liver histology for evaluation or prognosis.
\end{abstract}

Sahlgrenska Hospital, Göteborg R Olsson

Medical Clinic, Östra Hospital, Göteborg S Wallerstedt

Medical Clinic, Huddinge Hospital, Stockholm U Broomé

Medical Clinic, University Hospital, Umeá

Å Danielsson

Medical Clinic, Regional Hospital, Örebro

G Järnerot

Medical Clinic, University Hospital, Uppsala

L Lööf

Medical Clinic, University Hospital, Lund

H Prytz

Medical Clinic, University Hospital, Linköping

B-O Rydén

Department of Pathology, Lund Infirmary, Lund I Hägerstrand

Correspondence to: Dr R Olsson, Medical Clinic, Sahlgrenska sjukhuset, S-413 45 Göteborg,

Sweden.
Accepted for publication 9 March 1995 (f Clin Pathol 1995;48:933-935)

Keywords: Sampling variability, primary sclerosing cholangitis.

Liver biopsy is essential for the diagnosis and control of liver disease. The risk of sampling error has been evaluated in both postmortem studies and in living patients. ${ }^{1-6}$ There is general agreement that liver biopsy is an accurate method for diagnosing diffuse changes in the liver, such as fatty infiltration, acute and chronic hepatitis and venous congestion. There is considerable sampling error, however, in macronodular cirrhosis, although less so in micronodular cirrhosis. None of the reports published on sampling variability have dealt with primary sclerosing cholangitis (PSC). The aim of the present study was to evaluate sampling variability as a part of a double blind, multicentre study of the use of colchicine in the treatment of this disease, reported elsewhere. ${ }^{7}$

\section{Methods}

The investigation was performed by members of the Swedish Internal Medicine Liver Club (SILK). Percutaneous liver biopsy specimens were obtained, using a Menghini needle ( $1 \cdot 4$ to $1.6 \mathrm{~mm}$ in diameter), from 44 patients with PSC, 30 of whom had inflammatory bowel disease, before and/or after three years of treatment with colchicine or placebo. The diagnosis of PSC was confirmed by cholangiography. The clinical trial included 84 patients and although we intended to take two specimens at each biopsy, this was possible on only 56 occasions giving 112 specimens in total. The main constraint was concern about complications. The biopsies were performed by different physicians - that is, not only by the principal investigator at each centre. During the biopsy procedure, the needle was introduced twice in different directions through the same puncture.

The liver biopsy specimens were fixed in $4 \%$ formaldehyde and embedded in paraffin wax. Several sections were cut and stained with haematoxylin and eosin, periodic acid Schiff, with and without diastase treatment, and for collagen, iron, bile, and reticulin. The slides were assessed blindly by one of the authors (IH).

The following characteristics were graded on a scale from 0 (normal) to 3 (severe): portal lymphocytic infiltration, portal fibrosis, bile duct and ductal proliferation, steatosis, cholestasis, and septal fibrosis-that is, septa of different lengths extending from the portal zone into the lobule and not necessarily porto-portal.

The following characteristics were noted as being present or absent: portal granuloma, periductal fibrosis, cirrhosis, and bile duct destruction-that is, inflammation, proliferation, atypia, necrosis, or atrophy of the duct epithelium. Each biopsy specimen was classified into one of five stages (including normal liver) according to Ludwig. ${ }^{8}$ With respect to the stage 3 classification, according to Ludwig the hallmark of stage 3 is the presence of porto-portal septa. In our opinion, however, such septa may occur even without portal fibrosis, the hallmark of stage 2 disease. In the present study, patients were only classified as having stage 3 disease when porto-portal septa were present together with portal fibrosis. A paucity of bile ducts and lobular change, including piecemeal necrosis, were only encountered occasionally and were not recorded.

In total, 112 biopsy specimens (56 pairs) from 44 patients were evaluated. Paired biopsy specimens from both the beginning and end of the three year treatment period were available for 12 patients.

Sampling variability was calculated in two ways: (1) qualitative analysis - that is, the percentage of biopsy specimen pairs showing disagreement with regard to a particular feature; and (2) quantitative analysis - that is, the percentage of biopsy pairs showing disagreement with regard to a feature on the scale from 0 to 
Table 1 Results of qualitative analysis of liver biopsy sampling variability in PSC, showing the number of biopsy pairs with a diagnostic feature in only one biopsy sample, out of the total number of biopsy pairs with the feature in at least one of the liver biopsy samples. The results for those 15 pairs of biopsy samples in which both samples were $\geq 2 \mathrm{~cm}$ in length are included. The overall occurrence of each feature in all 112 biopsy samples is also given

\begin{tabular}{|c|c|c|c|c|c|}
\hline Feature & $\begin{array}{l}\text { Total no. of biopsy } \\
\text { specimen pairs }(n=56)\end{array}$ & Disagreement & $\begin{array}{l}\text { Both biopsy specimens } \\
\geq 2 \mathrm{~cm}(n=15)\end{array}$ & Disagreement & $\begin{array}{l}\text { Overall } \\
\text { occurrence (\%) }\end{array}$ \\
\hline Portal lymphocyte infiltration & $11 / 44$ & $(25 \%)$ & $3 / 12$ & $(25 \%)$ & 69 \\
\hline Portal fibrosis & $10 / 50$ & $(20 \%)$ & $5 / 12$ & $(42 \%)$ & 80 \\
\hline Septal fibrosis & $7 / 39$ & $(18 \%)$ & $1 / 8$ & $(23 \%)$ & 63 \\
\hline Bile duct proliferation & $8 / 24$ & $(34 \%)$ & $1 / 4$ & $(25 \%)$ & 36 \\
\hline Steatosis & $2 / 8$ & $(25 \%)$ & $1 / 3$ & & 13 \\
\hline Cholestasis & $4 / 6$ & $(67 \%)$ & $0 / 0$ & & 7 \\
\hline Cirrhosis & $3 / 8$ & $(37 \%)$ & $0 / 1$ & & 12 \\
\hline Bile duct destruction & $5 / 7$ & $(71 \%)$ & $2 / 3$ & & 8 \\
\hline Periductal fibrosis & $3 / 6$ & $(50 \%)$ & $1 / 2$ & & 8 \\
\hline Granuloma & $1 / 2$ & $(50 \%)$ & $0 / 1$ & & 3 \\
\hline
\end{tabular}

Table 2 Results of the quantitative analysis of liver biopsy sampling variability in PSC, showing the percentage of biopsy pairs differing a scale from 0 to 3. For all features without stages, the feature was classified on a scale from 0 to 3 and for stages on a scale from 0 to 4. The results for the 15 pairs of biopsy samples $\geq 2 \mathrm{~cm}$ in length are also given

\begin{tabular}{|c|c|c|c|c|c|c|c|c|c|c|}
\hline \multirow[b]{2}{*}{ Disagreement (grade) } & \multicolumn{5}{|c|}{ Total $(n=56)$} & \multicolumn{5}{|c|}{ Both biopsy specimens $>2 \mathrm{~cm}(n=15)$} \\
\hline & 0 & 1 & 2 & 3 & 4 & 0 & 1 & 2 & 3 & 4 \\
\hline $\begin{array}{l}\text { Portal lymphocyte infiltration } \\
\text { Portal fibrosis } \\
\text { Periportal fibrosis } \\
\text { Bile duct proliferation } \\
\text { Cholestasis } \\
\text { Steatosis } \\
\text { Stage }\end{array}$ & $\begin{array}{l}68 \\
63 \\
71 \\
80 \\
93 \\
96 \\
73\end{array}$ & $\begin{array}{r}29 \\
34 \\
27 \\
14 \\
7 \\
4 \\
16\end{array}$ & $\begin{array}{l}3 \\
2 \\
2 \\
6 \\
0 \\
0 \\
9\end{array}$ & $\begin{array}{l}0 \\
2 \\
0 \\
0 \\
0 \\
0 \\
2\end{array}$ & 0 & $\begin{array}{r}66 \\
66 \\
87 \\
87 \\
100 \\
93 \\
60\end{array}$ & $\begin{array}{r}33 \\
33 \\
13 \\
13 \\
\\
7 \\
33\end{array}$ & $\begin{array}{l}0 \\
0 \\
0 \\
0 \\
\\
0 \\
7\end{array}$ & $\begin{array}{l}0 \\
0 \\
0 \\
0 \\
0 \\
0\end{array}$ & 0 \\
\hline
\end{tabular}

3. This analysis was restricted to staging and to the six features subjected to grading (see above).

\section{Results}

Of the 112 biopsy specimens, 47 were $>2 \mathrm{~cm}$ in length. For 15 pairs, both biopsy samples were $>2 \mathrm{~cm}$ in length. On histology, 10 patients had stage 0 , eight stage 1,18 stage 2,13 stage 3 , and seven stage 4 disease.

The results are summarised in tables 1 and 2. The overall occurrence of the 10 histological features in the 112 biopsy specimens is also shown in table 1 . The different features evaluated in the biopsy specimens showed qualitative sampling variabilities of between 18 and

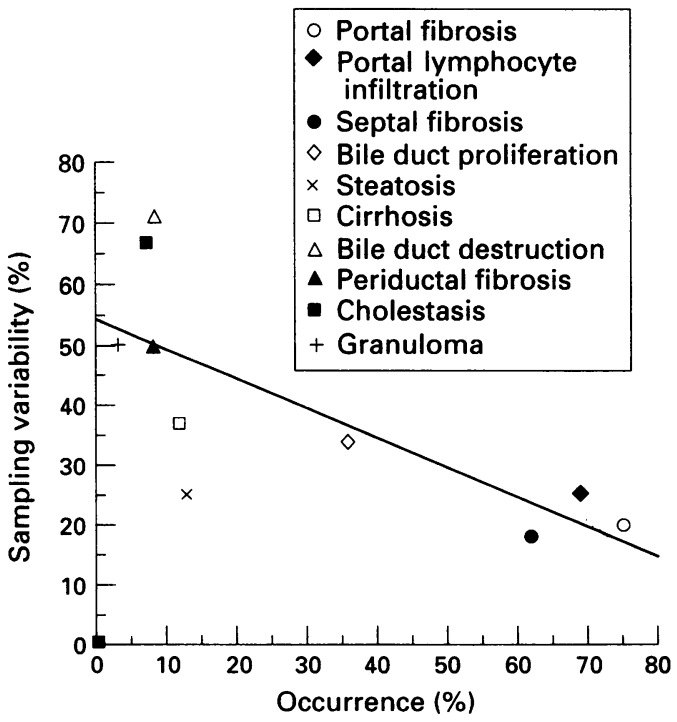

Correlation between the occurrence of different histopathological features and sampling variability $\left(r^{2}=0.57, p=0.012\right)$
$71 \%$. There was no consistent improvement in sampling variability in the subsample of biopsy specimens in which both samples were $\geq 2 \mathrm{~cm}$ in length. Quantitative sampling variability was confined mainly to just a single grade or stage. However, $11 \%$ (six of 56 ) of the biopsy specimen pairs differed by more than one stage. This figure was reduced to $7 \%$ (one of 15) when both samples were $\geq 2 \mathrm{~cm}$ in length. Advanced disease (stages 3 or 4 ) was diagnosed in 22 patients. In six (27\%) of these, one biopsy specimen in the pair was classified as stage 0 , 1 or 2 . When the analysis was restricted to the 15 pairs in which both biopsy specimens were $>2 \mathrm{~cm}$ in length, advanced disease was missed in $40 \%$ (two of five) of patients.

\section{Discussion}

Portal fibrosis and portal lymphocytic infiltration were the most common histological features noted (table 1), which is consistent with the early evolution of the disease. From a diagnostic point of view, the most important histological abnormalities are bile duct destruction and periductal fibrosis. These abnormalities were observed in only $8 \%$ of the biopsy specimens, a figure considerably lower than that recorded in previous reports. ${ }^{9-11}$ This anomaly may have come about because more patients in this study had stage 0 to 2 disease. The most common pathological finding was thin, non-bridging, perilobular, fibrous septa. The lack of diagnostic changes emphasises that the diagnosis of PSC must be based on the characteristic cholangiographic manifestations of the condition and not on histology. Nevertheless, liver biopsy is recommended in PSC as a prognostic feature in survival models. ${ }^{12}$ In view of this, determination of the sampling variability in liver biopsy is essential. 
It should be pointed out, however, that the present study does not provide any information on the sensitivity of needle biopsy for detecting different histological features in PSC-that is, the probability of detecting each of the different histological features of the disease in a single biopsy specimen. Such a study would have required a comparison of needle biopsy samples with considerably larger liver samples obtained, for example, at necropsy. Our data show, however, that there is at least a $20 \%$ risk of missing important features on blind needle biopsy (table 1). Sensitivity was not improved when the length of both biopsy samples was at least $2 \mathrm{~cm}$. Cirrhosis was consistently diagnosed in only $63 \%$ of paired biopsy specimens. Thus, examination of a single biopsy specimen could result in this diagnosis being missed in $37 \%$ of patients. Similar variability has been found in various types of cirrhosis..$^{3-8}$ As anticipated, the sampling variability of a feature was related to the overall occurrence of this feature (figure), thus steatosis, cholestasis and bile duct destruction appear as outliers. As no sampling variability was reported for steatosis in a previous series of 25 patients, ${ }^{2}$ our figure of $25 \%$ is unexpectedly high. The high sampling variability for bile duct destruction ( $71 \%$ ) is notable as this is considered to be of high diagnostic value in PSC.

Quantitative analysis of liver biopsy sampling variability revealed minor disagreements (table 2). The most marked disagreements concerned staging; only $73 \%$ had no disagreement at all and $11 \%$ disagreed by more than one stage. Correlation between specimens in the subset in which both biopsy specimens were $>2 \mathrm{~cm}$ in length was no better, possibly because of the limited amount of material available. The relatively high sampling error of the staging procedure can be explained by the sampling variability of the different features that characterise staging, none of which have a sampling variability below $18 \%$ (table 1 ).

In many clinical studies patients are either described as having early (stages 1 or 2 ) or advanced (stages 3 or 4 ) disease. The present study demonstrates that there is a considerable risk $(40 \%)$ of missing advanced disease on examination of a single liver biopsy specimen, even if it is $>2 \mathrm{~cm}$ in length. This high figure was observed when biopsy specimens obtained on multiple passes at the same percutaneous site were compared. Had the study compared samples obtained from-for example, the right and left lobes of the liver, the difference would perhaps have been even greater.

We know from clinical experience that the different biochemical variables used in survival models show marked variations during the course of PSC. This study has demonstrated that the histological staging of needle biopsy specimens is also impaired by the considerable variation in the expression and severity of the disease in different parts of the liver. Paired biopsy specimens are recommended in studies using prognostic indexes including the histological stage and in those evaluating the results of therapeutic intervention.

The authors gratefully acknowledge the financial support of G.D. Searle Ltd.

1 Waldstein SS, Szanto PB. Accuracy of sampling by needle biopsy in diffuse liver disease. Arch Pathol 1950;50:326-8. 2 Abdi W, Millan JC, Mezey E. Sampling variability on percutaneous liver biopsy. Arch Intern Med 1979;139:667-9.

3 Soloway RO, Baggenstoss AH, Schoenfield LJ, Sommerskill WHJ. Observer error and sampling variability tested in WHJ. Observer error and sampling variability tested in
evaluation of hepatitis and cirrhosis by liver. Dig Dis 1971; 16:1082-6.

4 Baunsgaard P, Sanchez GC, Lundborg CJ. The variation of pathological changes in the liver evaluated by double biopsies. Arch Pathol Microbiol Scand (A) 1979;87:51-7.

5 Maharaj B, Maharaj RJ, Leary WP, Coppan RM, Naran $\mathrm{AD}$, Pirie $\mathrm{O}$, et al. Sampling variability and its influence on the diagnostic yield of percutaneous needle biopsy of the liver. Lancet 1989;i:523-5.

6 Vido I, Wildhirt E. Korrelation des laparoskopischen and histologischen Befundes bei chronischer Hepatitis und Leberzirrhose. Dtsch Med Wochenschr 1969;94:1633-7.

7 Olsson R, Broomé U, Danielsson A, Hägerstrand J, Järnerot $G$, Lööf L, et al. Colchicine treatment in primary sclerosing G, Löö L, et al. Colchicine treatment in primary sc.

8 Ludwig J. Surgical pathology of the syndrome of primary sclerosing cholangitis. Am f Surg Pathol 1989;33(Suppl 1):43-9.

9 Chapman RWG, Marborgh BAं, Rhodes JM, Summerfield JA, Dick R, Scheuer PJ, et al. Primary sclerosing cholangitis: a review of its clinical features, cholangiography and hepatic histology. Gut 1980;21:870-7.

10 Ludwig J, Barham SS, LaRusso NF, Elveback LR, Wiesner R, McCall JT. Morphologic features of chronic hepatitis associated with primary sclerosing cholangitis and chronic ulcerative colitis. Hepatology 1981;1:632-40.

11 Barbatis C, Grases P, Shepherd HA, Chapman RW, Trowell J, Jewell DPJ, et al. Histological features of sclerosing Cholangitis in patients with

12 Wiesner RH, Porayko MK, Dickson ER, Gores GJ, LaRusso NF, Hay JE. Selection and timing of liver transplantation in primary biliary cirrhosis and primary sclerosing cholangitis. Hepatology 1992;16:1290-9. 